\title{
Design and evaluation of Carvedilol nanocrystals sustained release tablets
}

\author{
Ashok Kumar Janakiraman ${ }^{1 *}$, Balan Sumathi ${ }^{2}$, T. Mohamed Saleem ${ }^{3}$, S. Ramkanth ${ }^{3}$, P. Odaya Kumar ${ }^{4}$, \\ Gopal Venkatachalam ${ }^{5}$ \\ ${ }^{1}$ Faculty of Pharmaceutical Sciences, UCSI University, Kuala Lumpur, Malaysia. \\ ${ }^{2}$ Department of Pharmaceutics, Al-Shifa College of Pharmacy. Perinthalmanna Kerala - 679325, India. \\ ${ }^{3}$ Annamacharya College of Pharmacy, Rajampet - 518126, Andhra Pradesh, India. \\ ${ }^{4}$ Department of Pharmaceutics, Kampala International University, Kiu Western Campus, Uganda. \\ ${ }^{5}$ Mother Theresa Postgraduate and Research Institute of Health Sciences, Puducherry- 605006, India.
}

\begin{tabular}{|c|c|}
\hline ARTICLE INFO & ABSTRACT \\
\hline Article history: & \multirow{9}{*}{$\begin{array}{l}\text { The present study was undertaken to develop and evaluate the carvedilol nanocrystals sustained release (SR) } \\
\text { tablets. The tablets were prepared by direct compression method using hydroxy propyl methyl cellulose } \\
\text { (HPMC) and ethyl cellulose (EC) polymers. The prepared tablets were evaluated in terms of their pre- } \\
\text { compression studies, post-compression parameters, in vitro dissolution and drug release kinetic. The tableting of } \\
\text { blend showed good pre-compression properties and the formulated tablets were exhibited desired post- } \\
\text { compression characters. The in vitro drug release were performed in the United States pharmacopoeia (USP) } \\
\text { apparatus-II (Paddle) using phosphate buffer (pH 6.8). The formulation CT5 was selected as the optimized } \\
\text { formulation by an in vitro drug release for } 24 \mathrm{hrs} \text { with the release of } 99.46 \% \text {. Drug release kinetics showed the } \\
\text { best fit to Higuchi's equation, and they exhibit diffusion dominated mechanism. The comparative in vitro } \\
\text { release study showed that the formulation CT5 has better control over the release of drug (99.46\%) when } \\
\text { compare to reference product ( } 73.64 \% \text { ) for } 24 \text { hrs. Thus overall result indicate that the carvedilol nanocrystal } \\
\text { using SR tablets is more discriminative approach for better release and prolong action. }\end{array}$} \\
\hline Rece & \\
\hline Acce & \\
\hline Available online: 30/04/2017 & \\
\hline Key words: & \\
\hline Carvedilol nanocrystals, & \\
\hline Sustained release, In vitro & \\
\hline dissolution and Drug release & \\
\hline kinetic. & \\
\hline
\end{tabular}

\section{INTRODUCTION}

Carvedilol is competitive adrenoreceptor antagonist that hinders the activity at the $\beta_{1}, \beta_{2}$, and $\alpha_{1}$-adrenergic receptors and exhibits a number of ancillary properties, such as antioxidant effects, inhibition of smooth muscle proliferation, and calcium antagonistic blocking activity. The original formulation of carvedilol is approved by the US Food and Drug Administration (FDA) to be administered twice daily and is widely used alone or in combination with other agents for the treatment of essential hypertension, mild-to-severe heart failure and myocardial infraction (Michal et al., 2006). Carvedilol (Biopharmaceutical classification system (BCS) class-II) is practically insoluble in

Corresponding Author

Ashok Kumar Janakiraman, Faculty of Pharmaceutical Sciences, UCSI

University, Kuala Lumpur, Malaysia. Email: akpharm @ gmail.com water, highly lipophilic and highly protein bound drug. Carvedilol undergoes significant stereo-selective first-pass metabolism, resulting in low absolute bioavailability (30\% or less). However, some sources suggest that this low bioavailability is the result of poor aqueous solubility (Odon et al, 2011). Low aqueous solubility puts a large burden on the oral bioavailability and absorption is dissolution rate-limited, which results in uneven and delayed the drug absorption. The solubility was improved by reducing the drug particle size into the nano (sub-micron) range. In this way, saturation solubility was increased, then dissolution rate and bioavailability related to the formulation of poorly soluble drugs could be enhanced (Tuomela et al., 2014; Ali et al., 2011). Consequently, a variety of new drug delivery systems have been investigated to overcome these limitations, such as nanosuspensions, nanoemulsions, solid lipid nanoparticles, solid dispersions, and liposomes (Dandan et al., 2014). 
Among these new formulation approaches, nanosuspensions are considered to be the most promising candidate for poorly water-soluble drugs due to their non-specific applicability. The resulting drug nanoparticles have an increased surface area and an enhanced solubility which in turn could result in substantial increases in drug dissolution rate and oral bioavailability (Sinha et al., 2013; Yu et al., 2015; Ashok Kumar et al., 2015).

Carvedilol nanosuspension could improve drug bioavailability after oral administration it showed fast drug release behavior and extensive fluctuations in plasma concentration (Liu et al., 2012). Conventional solid dosage form with nanocrystals will rise to pronounced fluctuations in plasma concentration and it is definitely harmful to patients with specific disease such as hypertension and diabetes. Therefore, it is necessary to develop a delayed delivery system of nanosuspensions to solve the problem. A once-daily, controlled-release (CR) formulation of carvedilol has been developed that provides levels of exposure similar to those achieved after administration of the current twice-daily formulation. Over a 24-hours period, carvedilol CR has been shown to maintain a steady plasma concentration time profile (Tenero et al., 2006).

Controlled release dosage form slows the discharge of the drug but do not offer a rapid and expected better onset of action (Ritesh et al., 2001). To avoid these limitations by proposing a new solution for poorly water-soluble drug carvedilol to be prepared into sustained release tablets in the form of nanocrystals. The carvedilol nanocrystals sustained release tablets consist of HPMC and EC, which are broadly used as a gelling agent in controlled release preparation. The prime objective of this study was to develop carvedilol nanocrystals SR tablets by adapting direct compression method using various ratio of HPMC and EC polymer for enhanced in vitro dissolution, prolong action and better patient compliance.

\section{MATERIALS AND METHODS}

\section{Materials used}

Carvedilol was obtained as a gift sample from Dr Reddy's laboratory limited, (Hyderabad, India), Ethyl cellulose and Microcrystalline cellulose (MCC) were obtained from Loba chemicals, (Mumbai, India). Hydroxy propyl methyl cellulose (HPMC) obtained from High media chemicals, (Bangalore, India), Magnesium stearate and Talc obtained from SD Fine chemicals (Mumbai, India). All other chemicals and reagent were of analytical grade.

\section{Methods}

\section{Preparation and physiochemical characterization of carvedilol nanocrystals}

Carvedilol nanocrystals were prepared by emulsiondiffusion (solvent exchange) method followed by high pressure homogenization with stabilizers. The prepared nanosuspension was oven-dried at $60^{\circ} \mathrm{C}$ for $12 \mathrm{hrs}$. The yield of the dried carvedilol nanocrystals were approximately $80 \%$. Physicochemical parameters such as appearance, color, odor, $\mathrm{pH}$, melting point, LOD, partition co-efficient, saturation solubility at various $\mathrm{pH}$ and morphology (SEM image) of carvedilol nanocrystals were described in our previous report, which shows significant results. (Ashok Kumar et al., 2015)

\section{Drug-excipient compatibility study}

Fourier transform infrared (FT-IR) spectrum of drug (carvedilol nanocrystals) and the combination of drug with excipients (physical mixture) were taken individually. Samples were compressed with potassium bromide and scanned between $4000-400 \mathrm{~cm}^{-1}$ in FT-IR (Analytical 2500, Germany). The change in spectra of the drug in the presence of excipients was investigated to identify the interaction of drug molecule with the excipients if any (Mutalik et al., 2007).

\section{Preparation of carvedilol nanocrystals $S R$ tablets}

Carvedilol nanocrystals were prepared by emulsiondiffusion (solvent exchange) method (Quintanar et al., 2005) followed by high pressure homogenization with stabilizers (Dolenc et al., 2009). Carvedilol nanocrystals SR tablets were prepared by direct compression method using the varying proportions of polymers in combination. The composition of various formulations of the tablets with their codes is listed in Table 1 . The excipients and active ingredients were individually passed through 60 mesh and 40 mesh sieve respectively. Calculated amount of the drug, polymers (HPMC and EC) and filler (MCC) was mixed thoroughly. Magnesium stearate and talc was added as lubricant and mixed for 10 minutes; the appropriate amount of the mixture was weighed and then compressed using a an eight station rotary press (Rimek Minipress, Ahmadabad, India) at a constant compression force equipped with a $12 \mathrm{~mm}$ flat-faced punches. The weight of all the tablets were kept constant i.e., 300 $\mathrm{mg}$ and stored in airtight containers for further study. Prior to compression, the blends were evaluated for their flow and compressibility characteristics.

\section{Pre-compression studies Angle of repose}

Angle of repose has been used to characterize the flow properties of solids. It is a characteristic related to interparticulate friction or resistance to movement between particles. A funnel was fixed at a height approximately $2-4 \mathrm{~cm}$ over the platform. The loose powder blend was slowly passed through the wall of the funnel, till the tip of powder cone formed just touched the tip of funnel stem. The height of the heap and radius was measured by using scale, the value of angle of repose is calculated by using the following formula (Rockville, 2002).

$$
\theta=\tan ^{-1} \frac{\mathrm{h}}{\mathrm{r}}
$$

Where, $\theta$ is angle of repose, $h$ is the height of heap, and $r$ is the radius of base of heap circle. 


\section{Total porosity}

Total porosity was determined by measuring the volume occupied by a selected weight of a powder $\left(\mathrm{V}_{\text {bulk }}\right)$ and the true volume (the space occupied by the powder exclusive of spaces greater than the intermolecular space, V) of blend (Martin, 2001).

$$
\text { Porosity }(\%)=\frac{\text { Vo }- \text { Vf }}{\text { Vo }}
$$

Where, $\mathrm{V}_{\mathrm{o}}$ is the initial volume of blend in graduated cylinder, and $\mathrm{V}_{\mathrm{f}}$ is the final volume of blend in graduated cylinder.

\section{Moisture content}

The moisture content values of the physical mixture (blend) were determined using a moisture balance (Sartorius MA 150 , Germany) fitted with an infrared heating unit. The balance was preheated to $80{ }^{\circ} \mathrm{C}$ for 10 minutes and the drug sample $(\sim 1$ gm) was heated for a further 30 minutes at this temperature and record the moisture content (Pather et al., 1998).

\section{Post-compression parameters}

The prepared tablets were characterized for general appearance, weight variation, friability, drug content, tensile strength and elastic recovery to meet the pharmacopoeial standards and/or in house specification (Martin, 2001; Wells, 2002).

\section{Tensile strength}

Tensile strength is the stress at which a material breaks or permanently deforms. It is an intensive property independent of the size of the tested tablet (Andrej et al., 2009). It was measured diametrically using tablet hardness tester (Campbell electronics, Mumbai, India). The tensile strength of the tablets was calculated by formula.

$$
\text { Tensile strength }=\frac{2 \mathrm{~F}}{\pi \mathrm{dh}}
$$

Where, $\mathrm{F}$ is the rushing force of tablets, $\mathrm{d}$ is the diameter of tablets, and $\mathrm{h}$ is the thickness of tablets.

\section{Elastic recovery}

This quantity, the degree of the expansion after removal of the compression forces and it was measured one day after compression (Andrej et al., 2009). Elastic recovery was calculated using the formula.

$$
\text { Elastic recovery }=\frac{\mathrm{h} \text { punch }-\mathrm{h} \text { tablet }}{\mathrm{h} \text { punch }} \times 100
$$

Where, $h_{\text {punch }}$ is the distance between punches (upper and lower), and $h_{\text {tablet }}$ is the weight of the tablet measured 1 day after compression.

\section{In vitro dissolution study}

The in vitro dissolution of carvedilol nanocrystals SR tablets were performed using USP dissolution apparatus (Electrolab, Mumbai, India) type-II (Paddle). The studies were carried out using $900 \mathrm{ml}$ of phosphate buffer solution (pH 6.8) as dissolution medium. The studies were performed at a temperature of $37 \pm 0.5{ }^{\circ} \mathrm{C}$ with $100 \mathrm{rpm}$ speed for $24 \mathrm{hrs}$. The tablets were placed in dissolution jar and an aliquot of $5 \mathrm{ml}$ was withdrawn at an interval of $1 \mathrm{hr}, 4 \mathrm{hrs}, 8 \mathrm{hrs}, 12 \mathrm{hrs}, 16 \mathrm{hrs}, 20 \mathrm{hrs}$ and $24 \mathrm{hrs}$ respectively. The same volume of pre warmed $\left(37 \pm 0.5^{\circ} \mathrm{C}\right)$ fresh dissolution medium was replaced each time. The samples were filtered through $0.45 \mu \mathrm{m}$ membrane filter. Samples were suitably diluted with phosphate buffer solution and assayed for carvedilol nanocrystals concentration using HPLC method. Drug dissolved in specified time periods were plotted as cumulative percentage drug release versus time (hrs) curve. In vitro dissolution of reference product (carvedilol SR tablets were prepared by using optimized batch excipient concentration) was carried out in the similar manner and the results were compared with optimized formula.

\section{Drug release kinetics}

The dissolution data obtained was fitted to zero order (cumulative amount of drug released vs time), first-order (log cumulative percentage of drug remaining vs time), Higuchi's (cumulative percentage of drug released vs square root of time), Hixson-Crowell (cubic root of percent drug release vs time) and Korsmeyer-Peppas (log cumulative percentage of drug released vs $\log$ time) equations to understand the rate and mechanism of carvedilol nanocrystals release from the prepared formulations. The PSP-DISSO V2 software, developed in-house was used to study the release kinetics parameters for formulation in phosphate buffer ( $\mathrm{pH}$ 6.8). The correlation coefficients were calculated and used to find the fitness of the data. The diffusion exponent (n) for different batches of tablets, the value of $n \leq 0.45$ indicates Fickian (case I) release; > 0.45 but $<0.89$ for non-Fickian (anomalous) release; and $>0.89$ indicates super case II type of release. Case II generally refers to the erosion of the polymeric chain, and anomalous transport (Non-Fickian) refers to a combination of both diffusion and erosion-controlled drug release (Shato et al., 1997).

\section{Accelerated stability studies}

The accelerated stability study $\left(40 \pm 2^{\circ} \mathrm{C} / 75 \pm 5 \% \mathrm{RH}\right)$ of the CT5 formulation tablets were carried out according to $\mathrm{ICH}$ guideline for six months by storing the sample in stability chamber. At the interval of 1, 2, 3 and 6 months, tablets were withdrawn and evaluated for physical appearance, weight variation, thickness, friability, drug content, tensile strength and in vitro dissolution rate by the method described previously.

\section{RESULT AND DISCUSSION \\ Drug-excipient compatibility study}

The development of successful formulation depends only on the suitable selection of excipients. The compatibility study was performed to analyze the drug interaction with the excipients by FT-IR spectrum were shown in Figure 1. The different peaks of drug and their physical mixture indicate that all functional groups and characteristics of the drug were not altered. From the observation, it was conclude that there was no interference in the functional group as the principle peaks of carvedilol nanocrystals were found to be unaltered in the drug-excipient physical mixture. 


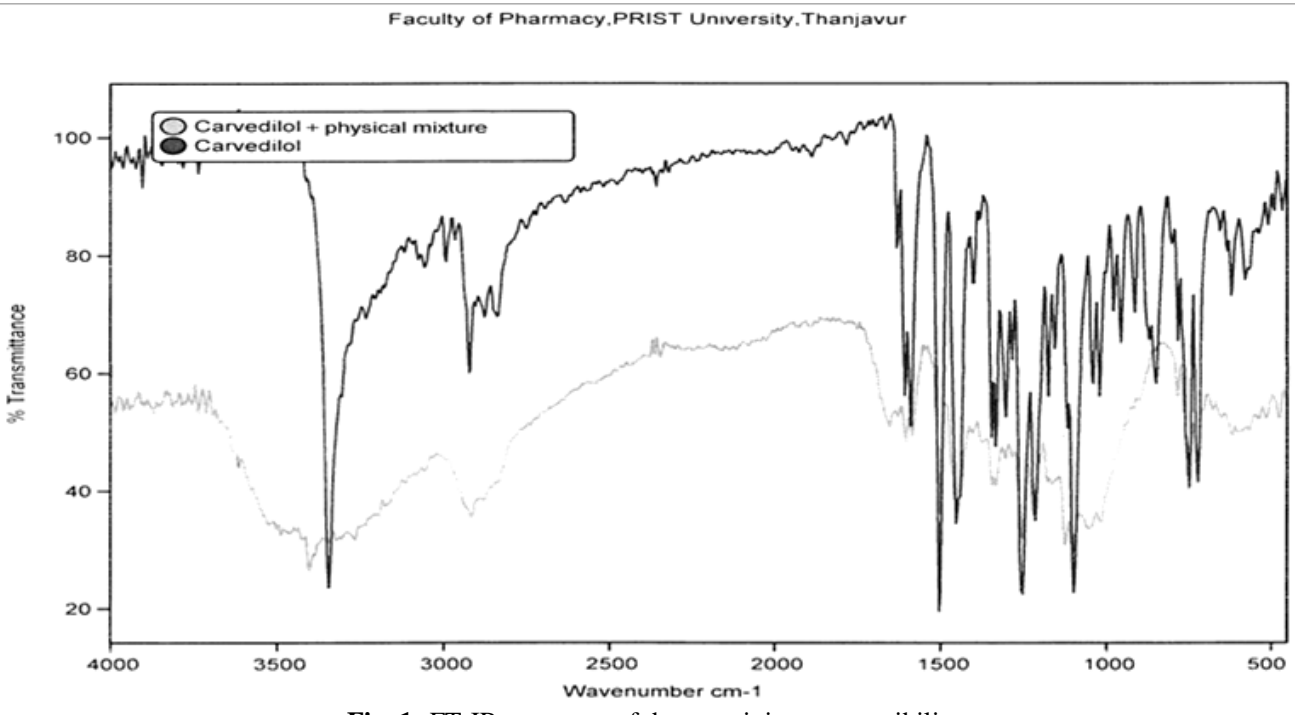

Fig. 1: FT-IR spectrum of drug-excipient compatibility

Table 1: Formulation composition.

\begin{tabular}{|c|c|c|c|c|c|c|c|c|c|}
\hline Ingredients (mg/tablet) & CT1 & CT2 & CT3 & CT4 & CT5 & CT6 & CT7 & CT8 & CT9 \\
\hline Carvedilol nanocrystals & 60 & 60 & 60 & 60 & 60 & 60 & 60 & 60 & 60 \\
\hline HPMC & 45 & 45 & 45 & 60 & 60 & 60 & 75 & 75 & 75 \\
\hline $\mathrm{EC}$ & 6 & 9 & 12 & 6 & 9 & 12 & 6 & 9 & 12 \\
\hline MCC & 180 & 177 & 174 & 165 & 162 & 159 & 150 & 147 & 144 \\
\hline Magnesium stearate & 3 & 3 & 3 & 3 & 3 & 3 & 3 & 3 & 3 \\
\hline Talc & 6 & 6 & 6 & 6 & 6 & 6 & 6 & 6 & 6 \\
\hline
\end{tabular}

\section{Preparation of carvedilol nanocrystals SR tablets}

In the present study carvedilol nanocrystals SR tablets were prepared by direct compression process as is known to be more economical than wet granulation and also avoid heat and moisture, which may affect the drug stability. A total number of nine formulations (CT1 to CT9) were prepared and evaluated for its pre-compression and post-compression parameters.

\section{Pre-compression studies}

Pre-compression parameters report were shown in Table 2. Angle of repose for various batches of the blend is found to be less than $28.81 \pm 0.04^{\circ}$, it indicate the good flow property. Angle of repose value more than $30^{\circ}$ indicate unsatisfactory flow properties of granules (Rashid et al., 2009).

The percentage porosity values of the granules ranged from $26.55 \pm 0.04$ to $29.56 \pm 0.06 \%$, indicating that the packing of the granules may range from close to loose packing and also further confirming that the particles are not of greatly different sizes. Generally, a percentage porosity value below $26 \%$ shows that the particles in the powders are of greatly different sizes and a value greater than $48 \%$ shows that particles in the powder are in the form of aggregates or flocculates. The proposed tablets components (blend) had moisture content value of less than $2 \%$, this property was not expected to adversely influence flowability. It is unlikely that the high moisture content of the excipients influences tableting characteristics. All these results indicate that the granules (blend) possessed satisfactory flow properties, compressibility, and moisture content were within the acceptable limits.

Table 2: Pre-compression stidies data

\begin{tabular}{cccc}
\hline $\begin{array}{c}\text { Formulation } \\
\text { code }\end{array}$ & $\begin{array}{c}\text { Angle of Repose } \\
\text { (degrees) }\end{array}$ & $\begin{array}{c}\text { Total porosity } \\
\mathbf{( \% )}\end{array}$ & $\begin{array}{c}\text { Moisture } \\
\text { content }(\boldsymbol{\%})\end{array}$ \\
\hline CT1 & $28.34 \pm 0.02$ & $29.50 \pm 0.08$ & $1.25 \pm 0.01$ \\
CT2 & $27.28 \pm 0.05$ & $27.23 \pm 0.07$ & $1.56 \pm 0.03$ \\
CT3 & $28.36 \pm 0.03$ & $28.23 \pm 0.06$ & $1.54 \pm 0.02$ \\
CT4 & $28.81 \pm 0.04$ & $29.56 \pm 0.06$ & $1.63 \pm 0.04$ \\
CT5 & $26.85 \pm 0.03$ & $26.55 \pm 0.04$ & $1.75 \pm 0.02$ \\
CT6 & $27.41 \pm 0.02$ & $27.33 \pm 0.05$ & $1.80 \pm 0.01$ \\
CT7 & $25.94 \pm 0.04$ & $29.50 \pm 0.06$ & $1.78 \pm 0.03$ \\
CT8 & $26.98 \pm 0.01$ & $27.24 \pm 0.08$ & $1.86 \pm 0.01$ \\
CT9 & $27.30 \pm 0.03$ & $28.23 \pm 0.07$ & $1.97 \pm 0.02$ \\
\hline
\end{tabular}

Mean \pm standard deviation, $\mathrm{n}=3$

\section{Post-compression parameters}

The tablets weight variation, friability, drug content, tensile strength and elastic recovery of each formulation are presented in Table 3. In determination of the tablet weights $(n=10)$, all formulations weights were found to be with in USP pharmacopoeial specification of 285 to $315 \mathrm{mg}$. The drug content uniformity of all tablet formulation was found to be $97.46 \pm 0.15$ to $101.43 \pm 0.16 \%$, which was within the limit of $90-110 \%$, and hence all the formulations passed the content uniformity as per USP pharmacopeia. The manufactured tablets showed low weight variation and a high degree of drug content uniformity in all 
Table 3: Post-compression parameters data

\begin{tabular}{|c|c|c|c|c|c|}
\hline Formulation code & $\begin{array}{c}\text { Weight variation } \\
\text { (mg) }\end{array}$ & $\begin{array}{c}\text { Tensile strength } \\
(\mathrm{MPa})\end{array}$ & Elastic recovery $(\%)$ & Friability (\%) & $\begin{array}{c}\text { Drug content } \\
(\%)\end{array}$ \\
\hline CT1 & $293.34 \pm 0.77$ & $1.98 \pm 0.01$ & $46 \pm 0.12$ & $0.89 \pm 0.01$ & $98.50 \pm 0.12$ \\
\hline CT2 & $296.55 \pm 0.75$ & $2.13 \pm 0.02$ & $42 \pm 0.17$ & $0.76 \pm 0.02$ & $99.02 \pm 0.18$ \\
\hline CT3 & $297.73 \pm 0.77$ & $2.12 \pm 0.01$ & $34 \pm 0.11$ & $0.82 \pm 0.01$ & $97.82 \pm 0.22$ \\
\hline CT4 & $296.84 \pm 1.17$ & $2.18 \pm 0.03$ & $38 \pm 0.24$ & $0.76 \pm 0.01$ & $98.46 \pm 0.14$ \\
\hline CT5 & $297.32 \pm 0.75$ & $2.31 \pm 0.01$ & $34 \pm 0.18$ & $0.73 \pm 0.02$ & $98.25 \pm 0.18$ \\
\hline CT6 & $300.56 \pm 2.26$ & $2.38 \pm 0.02$ & $38 \pm 0.16$ & $0.74 \pm 0.02$ & $101.43 \pm 0.16$ \\
\hline CT7 & $296.54 \pm 1.18$ & $2.43 \pm 0.02$ & $36 \pm 0.22$ & $0.73 \pm 0.01$ & $98.28 \pm 0.14$ \\
\hline CT8 & $296.25 \pm 2.14$ & $2.48 \pm 0.01$ & $38 \pm 0.16$ & $0.75 \pm 0.02$ & $99.76 \pm 0.16$ \\
\hline CT9 & $297.34 \pm 1.43$ & $2.62 \pm 0.03$ & $37 \pm 0.18$ & $0.68 \pm 0.01$ & $97.46 \pm 0.15$ \\
\hline
\end{tabular}

Mean \pm standard deviation

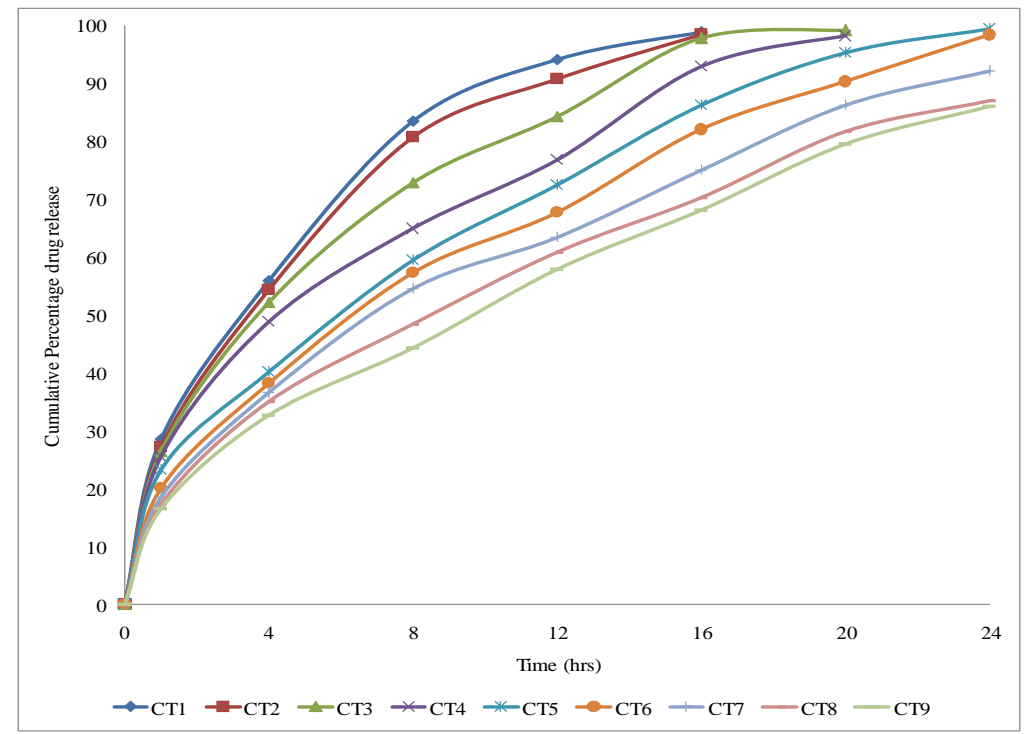

Fig. 2: In vitro drug release of carvedilol nanocrystals SR tablets

batches of the tablet formulation. Friability of the tablets was found to be $0.68 \pm 0.01$ to $0.89 \pm 0.01 \%$, well within acceptable range of $1 \%$ and indicate that tablets surface are strong enough to withstand mechanical shock or attrition during storage and transportation and until they are consumed (Lachman et al., 1986).

The tensile strength of the tablet was predominantly affected by the applied compression force. An increase in compression force resulted in much higher tensile strengths. As tensile strengths were closely correlated to dissolution rates and disintegration times (Esezobo and Pilple, 1977), there was hence a need to minimize the response. Tensile strength of carvedilol nanocrystals tablets were improved as the HPMC polymer concentration was increased. The amount of insoluble diluent (i.e microcrystalline cellulose) in the formulation also affected the tablet's tensile strength. The tensile strength of the all formulated batches was ranges from $1.98 \pm 0.01$ to $2.62 \pm 0.03 \mathrm{MPa}$, which were capable for withstanding the abrasion force during transit. Microcrystalline cellulose has been known to be a highly compactable excipient conferring strength to a tablet (Edge et al., 2001). Elastic recovery value ranges from $34 \pm 0.11$ to $46 \pm 0.12 \%$ in the case of tablet formulations compacted with carvedilol nanocrystals. This average value indicates that carvedilol nanocrystals interact with microcrystalline cellulose filler strongly. Tablets containing carvedilol nanocrystals need to be compacted with average force to reach pharmacopoeial standard. Higher forces result in greater deformation and more elastic behavior of tablets after the compacting force is removed. No increase in diameter of tablet after being expulsed from the matrix was observed, which indicate that no elastic recovery occurred after tablets ejection. Post-compression evaluation of carvedilol nanocrystal SR tablets complies with the standard pharmacopoeial limit and in-house specifications (IHS).

\section{In vitro dissolution study}

To establish the sink condition, we did not carry out the experiment directly, but in some reports (Odon et al., 2011) have stated that the drug does not possess sufficient solubility on acidic buffer ( $\mathrm{pH}$ 1.2), whereas it shows satisfactory solubility in phosphate buffer. For this reason, the phosphate buffer $\mathrm{pH} 6.8$ was chosen as dissolution medium. The in vitro dissolution profile of carvedilol nanocrystal SR tablets formulation CT1 to CT9 were shown in Figure 2. The in vitro dissolution results indicate that the release rate decreased as the concentration of HPMC increased. At higher polymer loading, the viscosity of gel matrix is increased which results in decrease in the effective diffusion coefficient of the drug and is more likely to be resistant to drug diffusion and erosion (Skoug et al., 1993; Wan et al., 1993).This indicates that drug/polymer ratio is important factor affecting the rate of release 
drugs from polymer matrices. Among the all formulations, the tablets prepared with HPMC 20 to $25 \%$ and EC 2 to $4 \%$ have shown greater drug release of not more than (NMT) $24 \%$ and not less than (NLT) $80 \%$ in $1 \mathrm{hr}$ and $20 \mathrm{hrs}$ respectively. Rate of drug release tend to decrease with increase in the content of either HPMC and/or EC. This finding similar with the literatures (Vazques et al., 1992; Ford et al., 1985), that the viscosity of the gel layer around the tablet increase with increase in the hydrogel concentration, thus limiting the release of the active ingredient.

\section{Drug release kinetics}

As data indicated in Table 4, the formulations did not follow a zero order pattern where the regression value of 0.7478 0.9824 . When the data were plotted according to the first-order equation, the formulations showed a fair linearity, with regression values between 0.8796 and 0.9868 . Release of the drug from a matrix tablet containing hydrophilic polymers generally involves factors of diffusion. Diffusion is related to transport of drug from the dosage matrix into the in vitro study fluid, depending on the concentration. This could explain why the drug diffuses at a comparatively slower rate as the distance for diffusion increases, which is referred as square-root kinetics or Higuchi's kinetics. In this experiments, the in vitro release profiles of drug from all the formulations showed high linearity with regression value of 0.9306 to 0.9988 , indicating that the drug release follows the Higuchi's equation, and diffusion is the dominating drug release mechanism. This finding is similar that of previously investigated work (Reza et al., 2003; Shanmugam et al., 2011 ). To confirm the diffusion mechanism, the dissolution data were fit into KorsmeyerPeppas equation, which is often used to describe the drug release behavior from polymeric system. As indicated in Table 4, CT1 to CT9 formulations showed good linearity (R2: 0.9527 to 0.9991 ), with slope $(n)$ values ranging from 0.3140 to 0.5556 , in which CT1 to CT5 exhibited Fickian type drug release, whereas CT6 to CT9 exhibited non-Fickian (anomalous) drug release.

Table 4: Drug release kinetic data.

\begin{tabular}{|c|c|c|c|c|c|c|}
\hline \multirow{2}{*}{ ن } & \multirow{2}{*}{ 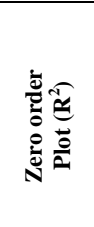 } & \multirow{2}{*}{ 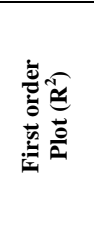 } & \multirow{2}{*}{ 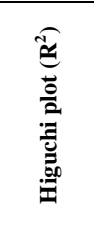 } & \multicolumn{2}{|c|}{$\begin{array}{c}\text { Korsmeyer-Peppas } \\
\text { plot }\end{array}$} & \multirow{2}{*}{ 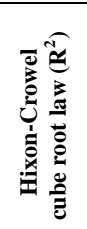 } \\
\hline & & & & (n) & $\left(\mathbf{R}^{2}\right)$ & \\
\hline CT1 & 0.7478 & 0.9226 & 0.9306 & 0.3140 & 0.9527 & 0.9070 \\
\hline CT2 & 0.7775 & 0.9227 & 0.9435 & 0.3331 & 0.9621 & 0.9217 \\
\hline CT3 & 0.8538 & 0.9469 & 0.9705 & 0.3748 & 0.9836 & 0.9633 \\
\hline CT4 & 0.9119 & 0.9448 & 0.9863 & 0.4176 & 0.9939 & 0.9754 \\
\hline CT5 & 0.9578 & 0.9852 & 0.9970 & 0.4304 & 0.9945 & 0.9861 \\
\hline CT6 & 0.9662 & 0.8796 & 0.9988 & 0.5272 & 0.9982 & 0.9801 \\
\hline CT7 & 0.9648 & 0.9727 & 0.9986 & 0.5151 & 0.9986 & 0.9907 \\
\hline CT8 & 0.9711 & 0.9868 & 0.9986 & 0.5195 & 0.9991 & 0.9904 \\
\hline CT9 & 0.9824 & 0.9827 & 0.9955 & 0.5556 & 0.9962 & 0.9924 \\
\hline
\end{tabular}

\section{Selection criteria for best formulation}

All formulations showed incomplete drug release of 100 $\%$ at the end of $24 \mathrm{hrs}$, except CT5 and CT6. According to the pharmacopoeial specification, it is seen that NMT $25 \%$ of the labeled amount of drug is getting released in first $1 \mathrm{hr}$, NLT $40 \%$ and NMT $60 \%$ of the labeled amount of drug in 8 hrs. NLT $80 \%$ of the labeled amount drug in 20 hrs, which were observed with CT5, CT6, CT7 and CT8 formulation. From the in vitro release data, CT5 formulation was best and its cumulative drug release was $99.46 \%$, when compare to other formulation. Concluded that, CT5 is showed the proper SR profile according to the pharmacopoeial limit. In addition CT5 formulation could be best expressed by Higuchi's equation, as the plot showed regression value of 0.9970 and also fitted to the exponential equation $\left(\mathrm{R}^{2}\right.$ : 0.9945 and $n=0.4304$ ). The carvedilol nanocrystals SR tablets formulation CT5 consisting HPMC and EC ratio of 22:3 showed suitable in vitro drug release and this batch was optimized for stability studies.

\section{Comparative in vitro drug release}

Reference product was subjected to evaluation of weight variation, tensile strength, friability and their value were shown in Table 5. The weight variation, tensile strength and friability of reference product tablets were found to be within the acceptable official limits.

Table 5: Reference product data.

\begin{tabular}{ll}
\hline Parameters & Observation \\
\hline Tablet weight $(\mathrm{mg})$ & $298 \pm 0.14$ \\
Tensile strength $(\mathrm{MPa})$ & $2.45 \pm 0.01$ \\
Friability $(\%)$ & $0.72 \pm 0.01$ \\
\hline
\end{tabular}

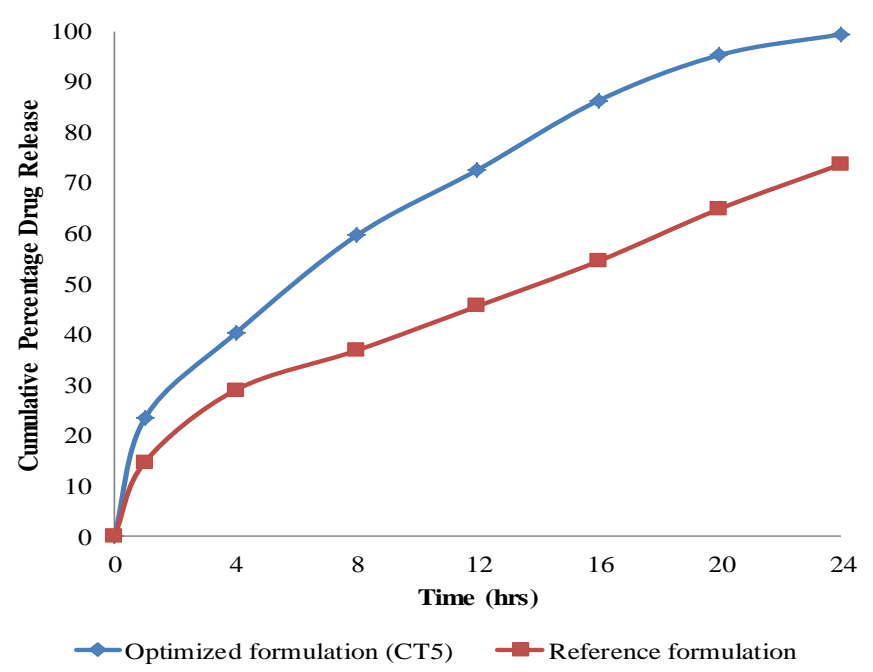

Fig. 3: Comparative in vitro drug release data.

The optimized carvedilol nanocrystals SR tablets (CT5) in vitro dissolution release profile was compared with reference product using same experimental condition as described previously. The comparative in vitro release studies results in Figure 3 indicate that the optimized carvedilol nanocrystals SR tablets (CT5) have shown a cumulative percent release of $99.46 \%$ in 24 hrs, while the opposite result found only $73.64 \%$. Furthermore, CT5 showed significantly higher in vitro dissolution rate as compare to reference product, due to enhanced surface area (nanocrystals) and sustained release. 
Table 6: Accelerated stability studies data.

\begin{tabular}{|c|c|c|c|c|c|c|}
\hline \multirow{2}{*}{ Parameters } & \multirow{2}{*}{ Specification } & \multirow{2}{*}{ Initial } & \multicolumn{4}{|c|}{$40 \pm 2^{\circ} \mathrm{C} / 75 \pm 5 \% \mathrm{RH}$} \\
\hline & & & 1 Month & 2 Months & 3 Months & 6 Months \\
\hline Physical appearance* & White, circular tablet, plain on both side & Complies & Complies & Complies & Complies & Complies \\
\hline Weight variation $(\mathrm{mg})$ & $285-315$ & Complies & Complies & Complies & Complies & Complies \\
\hline Thickness $(\mathrm{mm})^{*}$ & $2.60 \pm 0.10$ & Complies & Complies & Complies & Complies & Complies \\
\hline Tensile strength $(\mathrm{MPa})^{*}$ & $2.50 \pm 0.50$ & Complies & Complies & Complies & Complies & Complies \\
\hline Friability $(\%) * *$ & $<1$ & Complies & Complies & Complies & Complies & Complies \\
\hline Drug content $(\%) * *$ & $90-110$ & $98.25 \pm 0.18$ & $97.81 \pm 0.23$ & $98.31 \pm 0.12$ & $97.28 \pm 0.26$ & $96.48 \pm 0.14$ \\
\hline In vitro dissolution $(\%) * *$ & NLT 80 & 99.46 & 98.62 & 98.18 & 97.35 & 96.88 \\
\hline
\end{tabular}

* IHS, ** Revision Bulletin, United States Pharmacopoeial Convention. January 1, 2011.

\section{Accelerated stability studies}

Stability studies for optimized formulation (CT5) was carried out based on the accelerated condition at 1, 2, 3 and 6 months and the data were shown in Table 6. The results found satisfactory and revealed that the optimized formulation was stable up to 6 months as per ICH guidelines.

\section{CONCLUSION}

The finding of the study concluded that the precompression and post-compression parameters values are falling within the acceptable pharmacopoeial and IHS limits. In vitro dissolution study of CT5 formulation showed the maximum drug release $(99.46 \%)$ within $24 \mathrm{hrs,}$, when compare to other formulations. According to the in vitro release studies, the decrease in release rate was observed with an increase the concentration of polymers. Diffusion might be the drug release mechanism for all prepared tablets, which can be expressed by Higuchi's equation. The comparative in vitro release studies revealed that the release rate was depends on the polymers, particle size and physical nature of active ingredient. Special features of carvedilol nanocrystals are: further enlargement in surface area as compared to micronized powders, the increase in dissolution velocity and both leading to overcoming the rate-limiting step of oral absorption for BCS class II drug, carvedilol. Use of once-daily carvedilol nanocrystals tablets will provide the opportunity to simplify treatment regimens without sacrificing efficacy or tolerability, with important implications for improving blood pressure controls in patients with hypertension. Further studies will be conducted to evaluate thus SR tablets in vivo study for better therapy and improved patient compliance.

\section{ACKNOWLEDGEMENT}

The authors are thankful to PRIST University, Thanjavur, India for providing the facilities to complete this research work.

\section{Financial support and sponsorship: NIL.}

Conflict of Interests: There are no conflicts of interest.

\section{REFERENCES}

Ali HS, York P, Ali AM, Blagden N. Hydrocortisone nanosuspensions for ophthalmic delivery: a comparative study between microfluidic nanoprecipi-tation and wet milling. J Control Release 2011; 149: $175-181$.

Andrej D, Kristl J, Baumgartner S, Planinsek O. Advantages of celecoxib nanosuspension formulation and transformation into tablets, Int J Pharm, 2009; 376: 204-212.

Ashok Kumar J, Ramkanth S, Lakshmana Prabu S, Gopal V. Enhancement of saturation solubility and in vitro dissolution of carvedilol nanoparticles by high pressure homogenization technique. Int J Current Pharm Review and Research, 2015; 6(6): 269-273.

Dandan L, Shihui Y, Zhihong Z, Chunyang L, Chunping B, Huiqi G, Xinggang Y, Weisan P. Controlled delivery of carvedilol nanosuspension from osmotic pump capsule: In vitro and in vivo evaluation. Int J Pharm, 2014; 475: 96-503.

Dolenc A, Julijana K, Baumgartner S, Planinsek O, Advantages of celecoxib nanosuspension formulation and transformation into tablets, Int J Pharm, 2009; 376: 204-212.

Edge S, Steele DF, Tobyn MN, Staniforth JN, Chen A. Directional bonding in compacted microcrystalline cellulose, Drug Dev Ind Pharm, 2001; 27(7): 613-621.

Esezobo S, Pilple N. Formulation factors affecting strength and dissolution of uncoated oxytetracycline tablets. J Pharm Sci, 1977; 66: 852-858.

Ford JL, Rubinstein MH, Hongan JE. Formulation of sustained release promethazine hydrochloride tablets using hydroxypropyl methyl cellulose matrices, Int J Pharm, 1985; 24: 327-338.

Lachman L, Lieberman HA, Kanig JL. 1986. Theory and practice of industrial pharmacy, $3^{\text {rd }}$ Ed.; Varghese publishing house: Mumbai.

Liu D, Xu H, Tian B, Yuan K, Pan H, Ma S, Yang X, Pan W. Fabrication of carvedilol nanosuspensions through the anti-solvent precipitation-ultrasoni-cation method for the improvement of dissolution rate and oral bioavailability. AAPS Pharm Sci Tech, 2012; 13: 295-304.

Martin A. 2001. Micromeritics. In: Martin, A., Physical Pharmacy. Baltimore, MD: Lippincott Williams and Wilkins 423-454.

Michael AW, Domenic AS, Elizabeth AT, Malini I, Richard F, George LB. Controlled-Release Carvedilol in the Treatment of Essential Hypertension. Am J Cardiol, 2006; 98: 32-38.

Mutalik S, Naha A, Usha AN, Anju P, Ranjith AK, Musmade P, Manoj K, Prasanna K. Preparation, in vitro, preclinical and clinical evaluation of once daily sustained release tablets of aceclofenac, Arch Pharm Res, 2007; 30: 222-234.

Odon P, Borut K, Franc V. Carvedilol dissolution improvement by preparation of solid dispersions with porous silica. Int J Pharm, 2011; 406: 41-48.

Pather SI, Irina R, James AS, Steven HN, Sustained release theophylline tablets by direct compression. Part 1: Formulation and in vitro testing, Int J Pharm, 1998; 164: 1-10.

Quintanar GD, Tamayo ED, Ganem QA, Allemann E, Doekler E. Adaptation and optimization of the emulsification-diffusion technique to prepare lipidic nanospheres, Eur J Pharm Sci, 2005; 26: 11-18.

Rashid HO, Kabir AKL, Hossain MZ, Rauf ASS. Design and formulation of once daily naproxen sustained release tablet matrix from Methocel K 15M CR and Methocel K 100M CR, Iran J Pharm Sci, 2009; 5: 215-224. 
Reza MS, Quadir MA, Haider SS. Comparative evaluation of plastic, hydrophobic and hydrophilic polymers as matrices for controlled release drug delivery, J Pharm Pharm Sci, 2003; 6: 282-291.

Ritesh S, Sachin P, Hetal P, Sonia P, Shailesh S, Dinesh S, Development and validation of dissolution method for carvedilol compression-coated tablets. Braz J Pharm Sci, 2001; 40: 899-906.

Rockville MD. 2002. United State Pharmacopoeia 25/National Formulary 20, US Pharmacopoeial convention, Inc.

Shanmugam S, Chakrahari R, Sundramoorthy K, Ayyappan T, Vetrichelvan T. Formulation and evaluation of sustained release matrix tablets of losartan potassium. J Pharm Tech Res, 2011; 3: 226-234.

Shato H, Miyagawa Y, Okabe T, Miyajima M, Suanada H. Dissolution mechanism of diclofenac sodium from wax matrix granules, $\mathrm{J}$ Pharm Sci, 1997; 86: 929-934.

Sinha B, Muller RH, Moschwitzer JP. Bottom-up approaches for preparing drug nanocrystals: formulations and factors affecting particle size. Int J Pharm 2013; 453: 126-141.

Skoug JW, Mikelsons. MV, Vigneron. CN, Stemm NL. Qualitative evaluation of the mechanism of release of matrix sustained release dosage forms by measurement of polymer release. J Cont Rel, 1993; 27: 227-245.

Tenero DM, Henderson LS, Baidoo CA, Harter AH, Campanile AM, Danoff TM, Boyle D. Pharmacokinetic properties of a new controlled release formulation of carvedilol. Am J Cardiol, 2006; 98: 5-16.

Tuomela A, Liu P, Puranen J, Ronkko S, Laaksonen T, Kalesnykas G, Oksala O, Ilkka J, Laru J, Jarvinen K, Hirvonen J, Peltonen L. Brinzolamide nanocrystal formulations for ophthalmic delivery: reduction of elevated intraocular pressure in vivo. Int J Pharm 2014; 467: $34-41$.
Vazques MJ, Perez MB, Gomez ALJ, Martinez PR, Souto C. Inffluence of technological variables on release of drugs from hydrophilic matrices. Drug Dev Int Pharm, 1992; 18: 1355-1375.

Wan LS, Heng PW, Wong LF. Relationship between swelling and drug release in a hydrophilic matrix. Drug Dev Ind Pharm, 1993; 19 : 1201-1210.

Wells J. 2002. Pharmaceutical preformulation: The physiochemical properties of drug substances. In: Aulton, ME. Ed Pharmaceutics the science of dosage form design, London: Churchill Livingstone 244-47.

Yu G, Yongjun W, Lu X. Enhanced bioavailability of rebamipide nanocrystal tablets: Formulation and in vitro/in vivo evaluation. Asian J pharm sci. 2015, 10; 223-229.

\section{How to cite this article:}

Janakiraman AK, Sumathi B, Mohamed Saleem T, Ramkanth S, Odaya Kumar P, Venkatachalam G. Design and evaluation of Carvedilol nanocrystals sustained release tablets. J App Pharm Sci, 2017; 7 (04): 061-068. 